\title{
Mobilize at government doorsteps, CMA president urges
}

$\mathrm{W}$ hat do you do when you're facing what will likely be the busiest 12 months of your life? If you're Dr. John Haggie, the Canadian Medical Association's new president, you take it all in stride.

Sort of.

"My schedule already looks like someone took a 12-gauge shotgun and blew a hole in my calendar," Haggie says with a laugh.

Haggie, a surgeon and chief of staff at the James Paton Memorial Hospital in Gander, Newfoundland and Labrador, was officially handed CMA's reins on Aug. 24 at its 144th annual general meeting in St. John's, Newfoundland and Labrador. In his inaugural address, Haggie said dissatisfaction with the two-tier health care system in his native England "drove me 3000 miles west" in 1993, to the triangleshaped rock in the Atlantic ocean that is Canada's eastern-most province. Of course, the health care system he encountered on these shores was also far from perfect.

"As much as I have enjoyed living and working here, I was perplexed and concerned early on about many aspects of medical services delivery," Haggie told delegates. "Many of the issues I was concerned about then are the same ones we are still struggling with today accessibility, safe working conditions and timeliness of care are but a few examples."

Haggie is well aware of the challenges that await him as the face of Canada's medical profession. Canadians are worried that the health care system lacks the capacity to meet their needs, and that there are too few doctors to service a population that isn't getting any younger. It is up to physicians to give Canadian patients confi- dence by showing leadership and offering ideas on how to create an "enduring and robust system" that is sustainable

"We speak of a system as if it were a black box or impenetrable maze," Haggie said. "From the patient's perspective, it must appear so, as we now need navigators to negotiate its intricacies. Canadians want to make this monolith or maze accountable. They want to see each component accountable - user, provider and payer."

It was this desire to demystify the health care system that compelled Haggie to seek leadership roles in medicine (www.cmaj.ca/lookup /doi/10.1503/cmaj.109-3358).

The desire to answer questions such as "how can we make it better?" and "when are we going to fix it?" led him to join the Newfoundland and Labrador Medical Association and, in 2002, to run for and win its presidency. Haggie is also no stranger to the CMA, having served on its council on health policy and economics and its committee

and high in quality, said Haggie. And it is up to the CMA to put its health care transformation plan into action.

"Now that we have the plan, our challenge is to achieve some tangible results," Haggie said. "We need to mobilize at the doorstep of every provincial legislature and the Canadian parliament."

But physicians can't do it by themselves, Haggie acknowledged. They need feedback from patients, who are the "most important partner in health care." And they need help from other health care professionals. By making alliances and working together, he said, Canadians can have a better health care system. A system that provides timely and compassionate care for the acutely ill. A system that provides seamless and patient-oriented care for the chronically ill. A system that promotes wellness and prevention. A system that patients are no longer intimidated to enter. on education and professional development, among other roles.

Over the past year, as the CMA's president-elect, Haggie had the opportunity to travel to several of the association's town hall meetings. The experience taught him that both patients and doctors are concerned about the health care system, albeit in different ways, Haggie said in an earlier interview. "The public talked about how they interface with the black box," he says. "Physicians are interested in how the gears work."

Haggie is looking forward to addressing those concerns as Canada's top doc, a position he accepts with a healthy dose of jitters. "I'm nervous because I want to do a good job," he says. "But you need a bit of nerves to give you that extra bit of performance." — Roger Collier, CMAJ

CMAJ 2011. DOI:10.1503/cmaj.109-3987 